\title{
Cibercontrol al disseny i les arts digitals
}

Cybercontrol in Design and Digital Arts

Cibercontrol en el diseño y las artes digitales

\section{Anna Pujadas Matarín}

Eina, Centre Universitari de Disseny i Art

Universitat Autónoma de Barcelona

apujadas@eina.cat

Recibido: 05/11/2021

Aceptado: 11/01/2022 
Resum A la nostra vida quotidiana, utilitzant targetes de crèdit, càmeres web, etiquetant les nostres imatges a Facebook, navegant per una ciutat amb els nostres telèfons intel-ligents, participem constantment com a ciutadans en la societat de la vigilància. Contràriament, en el disseny i l'art la participació en les estratègies de vigilància esdevé una tàctica de crítica política i d'acció subversiva. En aquest article es ressenyen les obres i projectes d'artistes i dissenyadors digitals que s’institueixen com a agents polítics principals del discurs sobre la societat en xarxa. Són creadors que exploren críticament la manera en què les narratives postcapitalistes afecten l'alfabetització de les màquines, els humans i els ecosistemes. Les seves principals línies de recerca inclouen la materialitat d’Internet, la vigilància, la visualització de dades i les interfícies.

Paraules Art, cibercontrol, codi obert, disseny, multimèdia, vigilància.

clau

Abstract In our daily lives, using credit cards, webcams, tagging our images on Facebook, browsing a city with our smartphones, we constantly participate as citizens in the surveillance society. In contrast, in design and art of surveillance sharing these strategies becomes a tactic of political criticism and subversive action. This article reviews the works and projects of digital artists and designers who are the main political agents of the artistic discourse on the network society. They are creators who critically explore how post-capitalist narratives affect the literacy of machines, humans, and ecosystems. Her main lines of research include the materiality of the Internet, surveillance, data visualization and interfaces.

Keywords Art, Cybercontrol, Design, Mashup, Open Source, Surveillance.

Resumen En nuestra vida cotidiana, utilizando tarjetas de crédito, cámaras web, etiquetando nuestras imágenes en Facebook, navegando por una ciudad con nuestros smartphones, participamos constantemente como ciudadanos en la sociedad de la vigilancia. Contrariamente, en el diseño y el arte la participación en las estrategias de vigilancia deviene una táctica de crítica política y de acción subversiva. En este artículo se reseñan las obras y proyectos de artistas y diseñadores digitales que se instituyen como agentes políticos principales del discurso sobre la sociedad en red. Son creadores que exploran críticamente la manera en que las narrativas postcapitalistas afectan la alfabetización de las máquinas, los humanos y los ecosistemas. Sus principales líneas de investigación incluyen la materialidad de Internet, la vigilancia, la visualización de datos y las interfaces.

Palabras Arte, cibercontrol, código abierto, diseño, multimedia, vigilancia.

clave 


\section{Les tecnologies de vigilància al disseny i les arts digitals}

Segons l'estudiosa de la performance Elise Morrison, l'art de la vigilància es pot considerar un gènere particular d'activisme polític i d'actuació en què les tecnologies de vigilància (digitals), com ara les càmeres de CCTV i els dispositius GPS, s'utilitzen i s'apropien per crear una sèrie de coneixements tecnològics i polítics com a alternatives conscients i estèticament innovadores a les estructures actuals de poder i participació dins de la societat de vigilància (Morrison, 2015: 126-127).

En quin sentit substancial les arts i el disseny són útils per a una transformació o denúncia, o resistència, davant de les tecnologies de control? El periodista i informàtic bielorús Evgeny Morozov en la seva crítica al capitalisme digital considera que només amb pràctiques noves i innovadores que siguin impossibles de monetitzar perquè no existeix un mecanisme formal dins del capitalisme per descobrir-les i escalar-les correctament es pot aconseguir transformar la realitat. Aquest és el context en el qual s'emmarquen les pràctiques d'art i disseny centrades en la vigilància. Són pràctiques que no només exposen una ideologia de manera clara, on menys visible és i també on més es pot dinamitar, sinó que obren una línia teòrica per pensar en com desenvolupar tecnologies per crear realitats alternatives. Es tracta de moure's de tecnologies totalitàries, relativament instrumentals, cap a tecnologies que dissolguin el poder. Es tracta de fundar projectes que ofereixin una palanca política addicional a través de la qual es pugui crear un tipus diferent de societat (Morozov, 202: 217).

Dins del binomi entre art/disseny i activisme es donen diferents propostes clàssiques de treball, alternatives d'acció i pensament encaminades a crear noves relacions amb el poder o evidenciar les ja existents. Les estratègies que es poden utilitzar són diverses: desenvolupar una identitat col-lectiva que sorgeixi després de la creació i la difusió d'eines de coordinació i creació conjunta, consensuades per tots els participants; afavorir la multiplicitat dels actors i la interconnexió entre projectes, col-lectius, desenvolupadors i participants; apropiar-se de la tecnologia com a arma de poder que permet contrarestar estructures i procediments específics de control; la lluita contra el propi mitjà per evitar que l'acció sigui devorada per la mateixa tecnologia que la sustenta; crear espais de llibertat i experimentació amb un caràcter obert i públic aprofitant les oportunitats que brinda tant el programari lliure com les noves formes de comunicació i participació en xarxa; adoptar un rol de pioner o visionari, preveient i revelant els camins que oferirà el mercat digital, adaptant-ne nous usos i dispositius; cercar incessantment espais alternatius no vigilats, ni per l'aparell repressiu ni pel comercial (González, 2014: 358). 
Dins de l'ampli camp de l'art i la performance de vigilància, Morrison (2015) distingeix tres maneres en què l'art de vigilància pot interrompre i contrarestar la nostra societat de vigilància contemporània. En certa manera sintetitzen les estratègies anteriors i serviran d'estructura per ordenar els casos d'estudi d'aquest article. La primera via és la de la il-luminació crítica dels punts cecs de la societat de vigilància (com a mostra d'aquesta via s'aporta l'exemple de Joana Moll i Paolo Cirio); un segon camí és la intervenció física en els patrons habituals de moviment i d'usuari condicionats pel disseny estatal, militar i corporatiu de les interfícies de vigilància (com a exemple d'aquesta estratègia es presenta en aquest article el treball de Ben Grosser, Daniel Howe i Sang Mun); finalment hi ha l'orientació vers l'apropiació de tecnologies de vigilància amb finalitats subversives (les obres de Lozano-Hemmer en serviran de recolzament en aquest cas).

\section{Via I. Il-luminació crítica dels punts cecs de la societat de vigilància}

Al maig de 2017, Tactical Tech i l'artista Joana Moll van comprar un milió de perfils de cites en línia per $136 €$ a USDate, una empresa suposadament amb seu als Estats Units que comerciava amb perfils de cites de tot el món. Joana Moll és una artista i investigadora que explora críticament la manera en què les narratives postcapitalistes afecten l'alfabetització de les màquines, els humans i els ecosistemes. Les seves principals línies de recerca inclouen la materialitat d'Internet, la vigilància, l'anàlisi de perfils socials i les interfícies. El conjunt de perfils de cites que van comprar Moll i Tactical Tech incloïa imatges (gairebé 5 milions), noms d'usuari, adreces de correu electrònic, nacionalitat, sexe, edat i informació personal detallada sobre totes les persones que havien creat els perfils, com ara la seva orientació sexual, interessos, professió, característiques físiques exhaustives i trets de personalitat. A partir d'aquí van iniciar el seu projecte The Dating Brokers (2016) actualment en línia a Internet. És una pàgina web que revela el conjunt de dades del perfil de cites original que van rebre d'USDate després de comprar-lo. Per tal de protegir les identitats de les persones retratades als perfils, s'han eliminat i/o enfosquit qualsevol informació que pugui conduir a la identificació d'un usuari, com ara comptes de correu electrònic, adreces, números de telèfon o noms. La resta roman intacta. De la mateixa manera, Moll i Tactical Tech van fer tot el possible per anonimitzar els 5 milions d'imatges de perfil originals del conjunt de dades; no obstant això, a causa de limitacions tècniques, alguns d'ells podrien haver quedat sense ser anònims. Per solucionar aquest problema, van col-locar un botó a cada imatge per permetre que els espectadors informin d'imatges de perfil no anònimes. Aquest projecte intenta posar llum sobre pràctiques ben establertes a l'ecosistema global de cites en línia, que són crucials per al seu model de negoci però sobretot opaques per als seus usuaris. Joana Moll 
considera que aquestes pràctiques plantegen qüestions ètiques, morals i legals alarmants que s'han de resoldre amb urgència, ja que els perfils de cites contenen informació íntima sobre els usuaris i la sobreexplotació i el mal ús d'aquestes dades poden tenir efectes dramàtics en les seves vides (Moll, 2017).

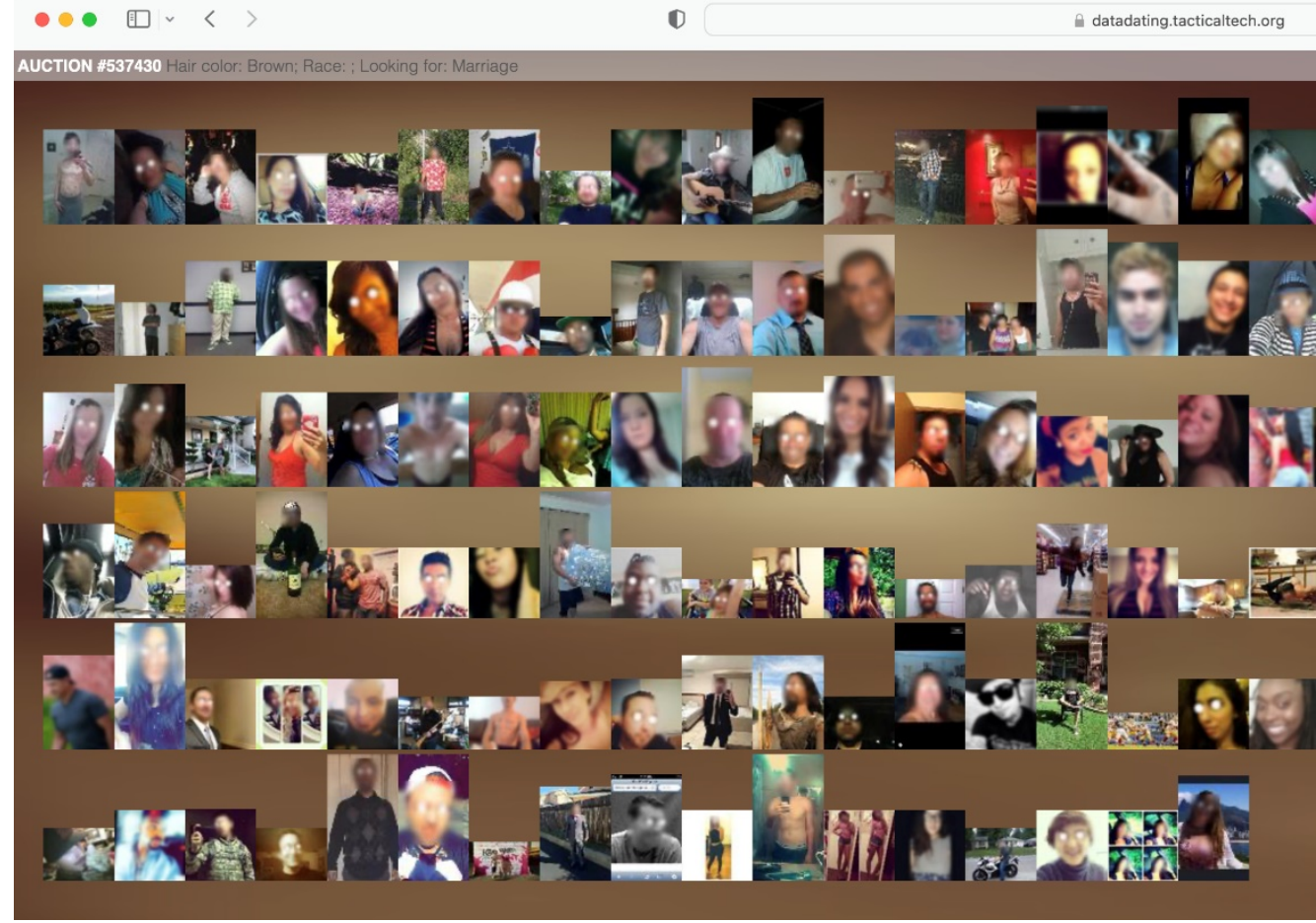

Captura de pantalla del projecte The Dating Brokers (2016) de Joana Moll \& Tactical Tech. CC BY-NC-SA. [online] Disponible a: https://datadating.tacticaltech.org/ Darrer accés: 10.01.2022

Aquesta obra d'art mediàtic (així la defineix l'autora) rescata, si bé en un altre context, l'obra de Paolo Cirio titulada Face to Facebook - Hacking Monopolism Trilogy (2011). Sota la definició d'escultor de dades, la trajectòria de l'italià Paolo Cirio creua de manera original tots els camps oberts per la revolució digital dels anys $90 \mathrm{i}$ especialment aborda els grans canvis de la concepció de l'esfera pública que va produir la xarxa 2.o. Aquesta obra d'art es va apropiar d'un milió de perfils de Facebook i en va publicar 250.000 en un lloc web de cites a mida amb perfils ordenats per temperament, que es van classificar a través de la intel-ligència artificial entrenada a analitzar les expressions facials. El lloc web de cites s'anomenava Lovely-Faces.com, on es proporcionava un escenari en el qual tothom pogués interactuar amb els trets de personalitat dels usuaris de Facebook, i seleccionar els que més agradaven, segons si eren simpàtics, senzills o astuts. El projecte es va desenvolupar durant cinc dies d'emocionants reaccions personals, mediàtiques i legals, que es van convertir en una fenomen mundial als mitjans de comunicació. Facebook el volia 
denunciar, les televisions ho relataven als noticiaris, les persones s'escandalitzaven. La pegunta era, perquè si ho fa Cirio és noticiable i en canvi, no ho és si ho fa Facebook? Pot un artista participar amb tecnologies de vigilància sense ser còmplice del seu ús per al control i l'opressió? Com pot presentar l'artista la seva obra com a comentari, més que com a mera reproducció? (Cirio, 2011).

Fa uns anys (2016) Paolo Cirio estava a Barcelona convidat pel MACBA. Se li va proposar realitzar la seva obra Streetghosts als carrers de la ciutat de Barcelona. Streetghosts era un projecte en el qual Cirio imprimia a mida real imatges de persones trobades a Google Street View i les col-locava, sense autorització, en el lloc on havien estat fotografiades, omplint els carrers de Barcelona de figures humanes amb cara borrosa a escala 1:1. Llavors ho fotografiava i ho tornava a documentar digitalment, de la mateixa manera com ho havia fet abans Google Street View. El cercle de l'exposició pública quedava així tancat (Cirio, 2016).

A The Virtual Watchers encara un projecte de recerca que està en curs, entre la intersecció de l'art, la investigació i la tecnologia, Joana Moll qüestiona la dinàmica del crowdsourcing a les fronteres estatals contemporànies. Se centra en els intercanvis que van tenir lloc dins d'un grup de Facebook que va reunir voluntaris nordamericans disposats a controlar la frontera entre EUA i Mèxic a través d'una plataforma en línia que mostrava projeccions en directe de càmeres de circuit tancat de televisió. L'objectiu declarat d'aquesta operació era aconseguir que els ciutadans nord-americans participessin en la reducció de la delinqüència fronterera i bloquejar l'entrada d'immigració il-legal als EUA mitjançant el crowdsourcing. Aquesta iniciativa d'una associació publicoprivada, es va llançar originalment el 2008 i consistia en una plataforma en línia anomenada RedServants i una xarxa de 200 càmeres i sensors situats a zones estratègiques al llarg de la frontera dels Estats Units amb Mèxic. Algunes d'aquestes càmeres també es van instal-lar a les propietats privades de ciutadans voluntaris. La plataforma en línia donava accés gratuït a les retransmissions de càmeres les 24 hores del dia i els 7 dies de la setmana i permetia als usuaris informar de manera anònima si notaven alguna activitat sospitosa a la frontera. En el seu projecte The Virtual Watchers Joana Moll exposa tota aquesta informació en una pàgina web navegable que permet al públic accedir a alguns dels canals de vídeo originals gravats per les càmeres de vigilància de RedServant, i permet submergir-se en les converses, acudits i preguntes del grup de Facebook que va reunir alguns dels ciutadans voluntaris que van utilitzar activament la plataforma. Òbviament Moll ha canviat el nom original de la plataforma per tal de protegir la identitat dels seus usuaris i totes les imatges de perfil i els noms reals dels membres del grup de Facebook han estat falsificats per protegir les seves identitats. Amb aquest projecte Joana Moll posa de manifest fins a quin punt la inversió emocional i els intercanvis d'aquestes persones funcionen com a mecanisme essencial en la construcció i legitimació d'un sistema post-panòptic (Moll, 2016). 


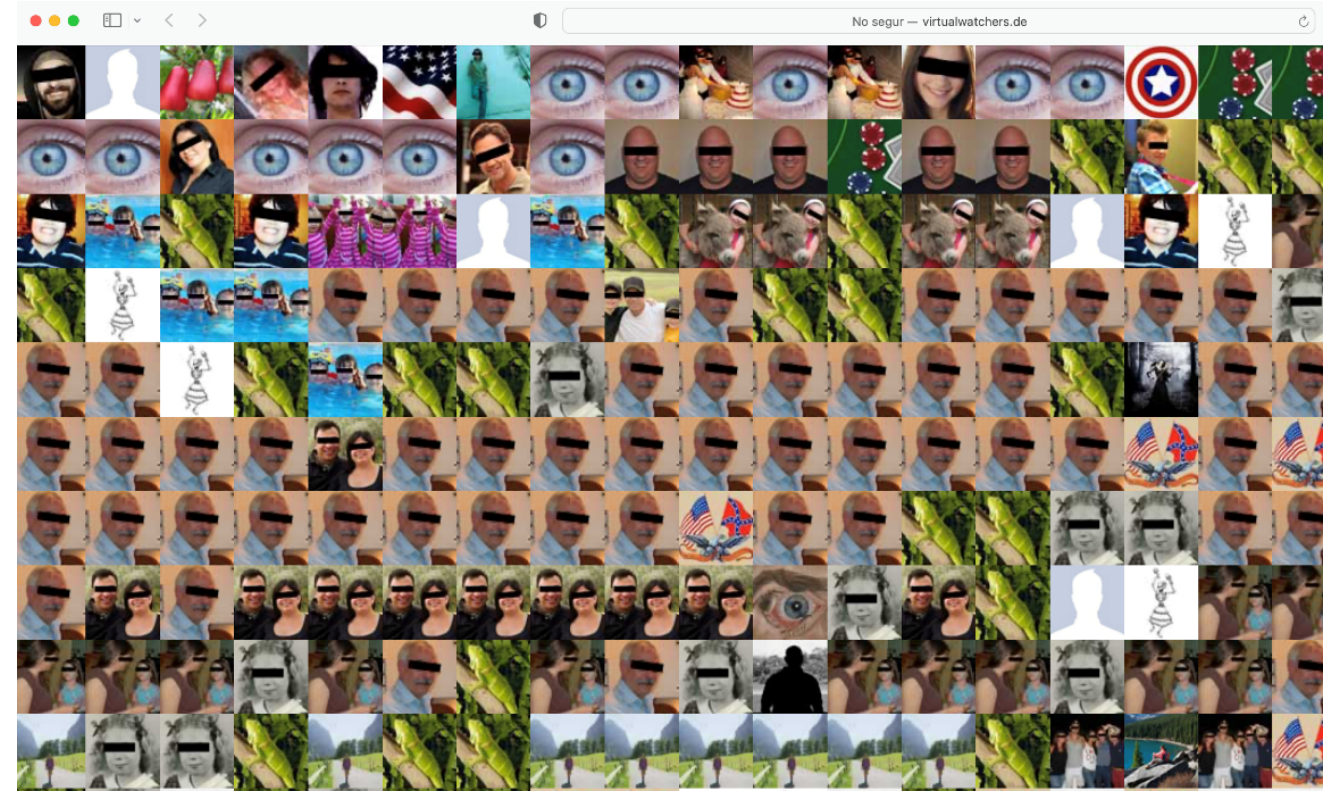

Captura de pantalla del projecte Virtual Watchers (2016) de Joana Moll. CC BY-NC-SA. [on-

line] Disponible a: http://www.virtualwatchers.de/ Darrer accés: 10.01.2022

Joana Moll denuncia que a la nostra societat algorítmica contemporània de presa de decisions, els ecosistemes es consideren cada vegada més com a simples externalitats econòmiques. Com es pot reticular la nostra relació amb el món si no som capaços de veure l'impacte real de les nostres accions en el món concret? Quin pot ser el paper de l'art digital en el reforç d'aquest procés? Quins canvis fonamentals cal produir en l'esfera de l'art per revelar les connexions entre accions i conseqüències, especialment quan aquestes accions estan mediades per la tecnologia? Són preguntes de la mateixa Moll. És crucial establir l'entorn com a agent polític principal del discurs sobre l'art de la societat en xarxa i crear mecanismes que puguin estimular i tornar a apropiar-se de la subjectivitat, un procés essencial en la generació de pensament crític sobre la veritable naturalesa de la tecnologia. Cal imaginar tecno-paradigmes alternatius que puguin respondre coherentment a les nostres condicions ambientals i humanes (Moll, 2016).

\section{Via II. Intervenció física en els patrons habituals de moviment i d'usuari condicionats per les interfícies de vigilància}

Marc Napier, l'artista canadenc pioner en art digital i netart té una peça clàssica encara en línia que s'anomena Riot (1999). Es tracta d'un navegador web alternatiu de cross-content. Com si fos un homònim del món real, Riot altera les normes de propietat acceptades i exposa la fragilitat de les fronteres territorials. Riot és un 
mashup (integració i reutilització) codificat per programari, una batedora que barreja pàgines web de dominis separats en una finestra del navegador. A diferència del navegador convencional, Riot crea la seva pàgina combinant text, imatges i enllaços de les pàgines recents a les quals ha navegat qualsevol usuari de Riot. Les marques del territori virtual: imatges, noms d'empresa, logotips corporatius, s'expressen en una sola pàgina. El contingut $\mathrm{i}$ les ideologies xoquen i es fusionen mentre Riot parteix d'URL diferents per crear una xarxa de fronteres canviants i mutables. Riot dissol les nocions tradicionals de territori, propietat i autoritat col-lapsant convencions territorials com dominis, llocs i pàgines. El resultat visual és un compost basat en l'atzar controlat, determinat per la imprevisibilitat i les accions de l'usuari, així com els paràmetres de visualització establerts per l'artista (Napier, 1999).

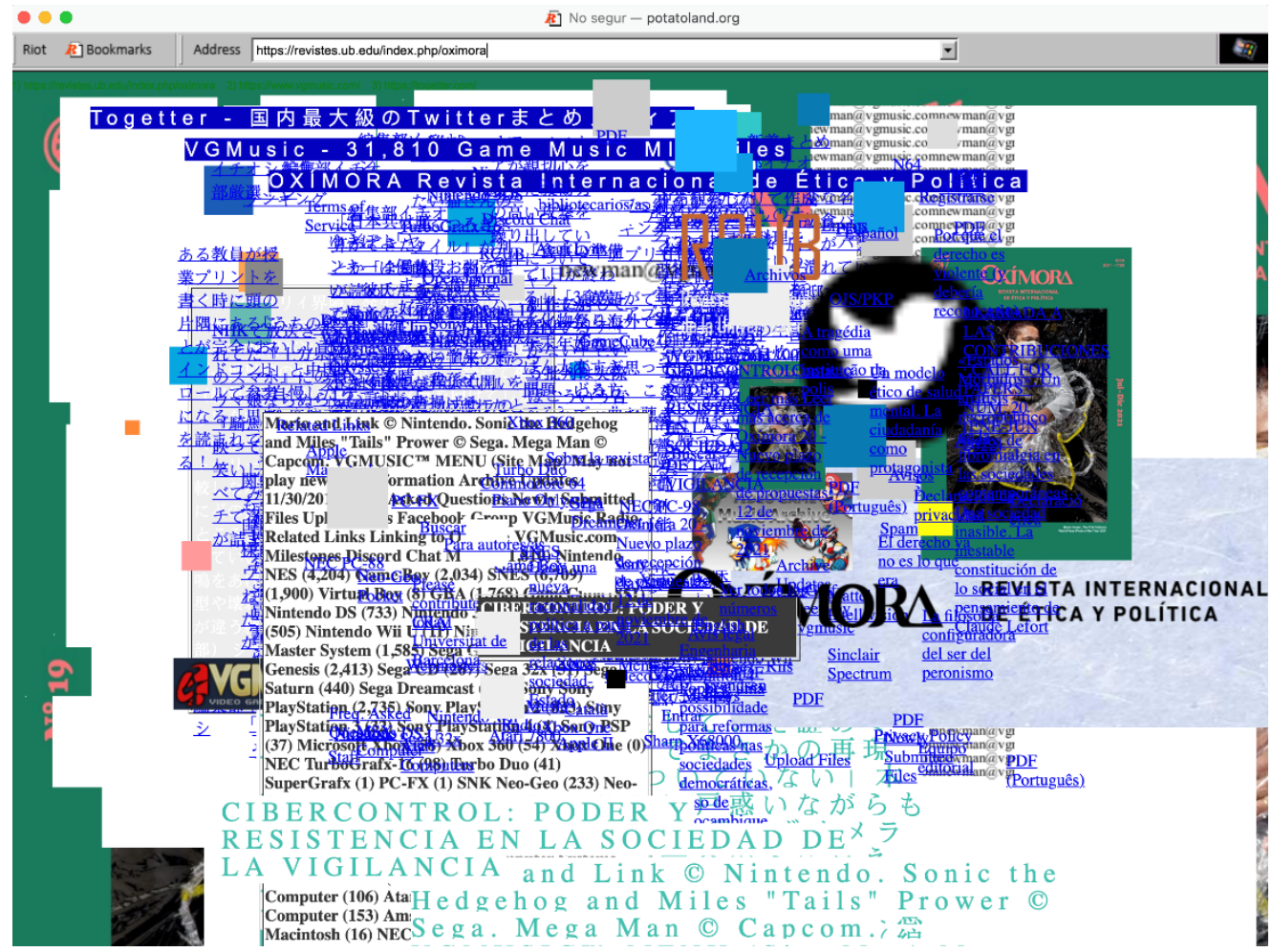

Captura de pantalla del mashup realitzat per Riot de Mark Napier barrejant el codi de la web de la revista OXÍMORA. CC BY-NC-SA. [online] Disponible a: http://potatoland.org/riot/ Darrer accés: 10.01.2022

Riot veu de les fonts d'una altra obra inaugural de Napier el famós Shredder (1998), un codi de programació que genera mashups de pàgines web simplement confonent la IA donant-li un descodificador equivocat. El web no és una publicació, ens recorda Napier. Els llocs web no són en paper. Tot i això, el pensament actual del disseny web és el de la revista, el diari, el llibre o el catàleg. Visualment, estèticament $\mathrm{i}$ legalment, el web es tracta com una pàgina física on s'escriuen text $\mathrm{i}$ 
imatges. Les pàgines web són imatges gràfiques temporals creades quan el programari de navegació interpreta instruccions HTML. Sempre que tots els navegadors estiguin d'acord en les convencions d'HTML, hi ha la il-lusió de solidesa o permanència al web. Però darrere de la il-lusió gràfica hi ha un ampli conjunt de fitxers de text (que contenen codi HTML) que omple els discs durs dels ordinadors ubicats a tot el món. En conjunt, aquestes instruccions constitueixen el que anomenem "web". Però, i si aquestes instruccions s'interpreten de manera diferent de la prevista? Potser radicalment diferent? Això és el que fa Marc Napier a The Shredder. El navegador web és un òrgan de percepció a través del qual "veiem" el web. Filtra i organitza una gran quantitat d'informació estructurada que abasta els continents, creix constantment, es reorganitza, canvia la seva aparença i evoluciona. The Shredder presenta aquesta estructura global com una action painting caòtica, irracional i descarnada. En alterar el codi HTML abans que el navegador el llegeixi, l'algoritme Shredder s'apropia de les dades del web, transformant-les en un web paral-lel. El contingut es converteix en abstracció. El text es converteix en gràfica. La informació es converteix en art (Napier, 1998). Napier està en aquella fina frontera entre l'apropiacionsime i la pirateria. En els seus mashups reprograma, reconfigura i reinicia, totes elles operacions que s'executen en informàtica i que són el terreny dels hacker.

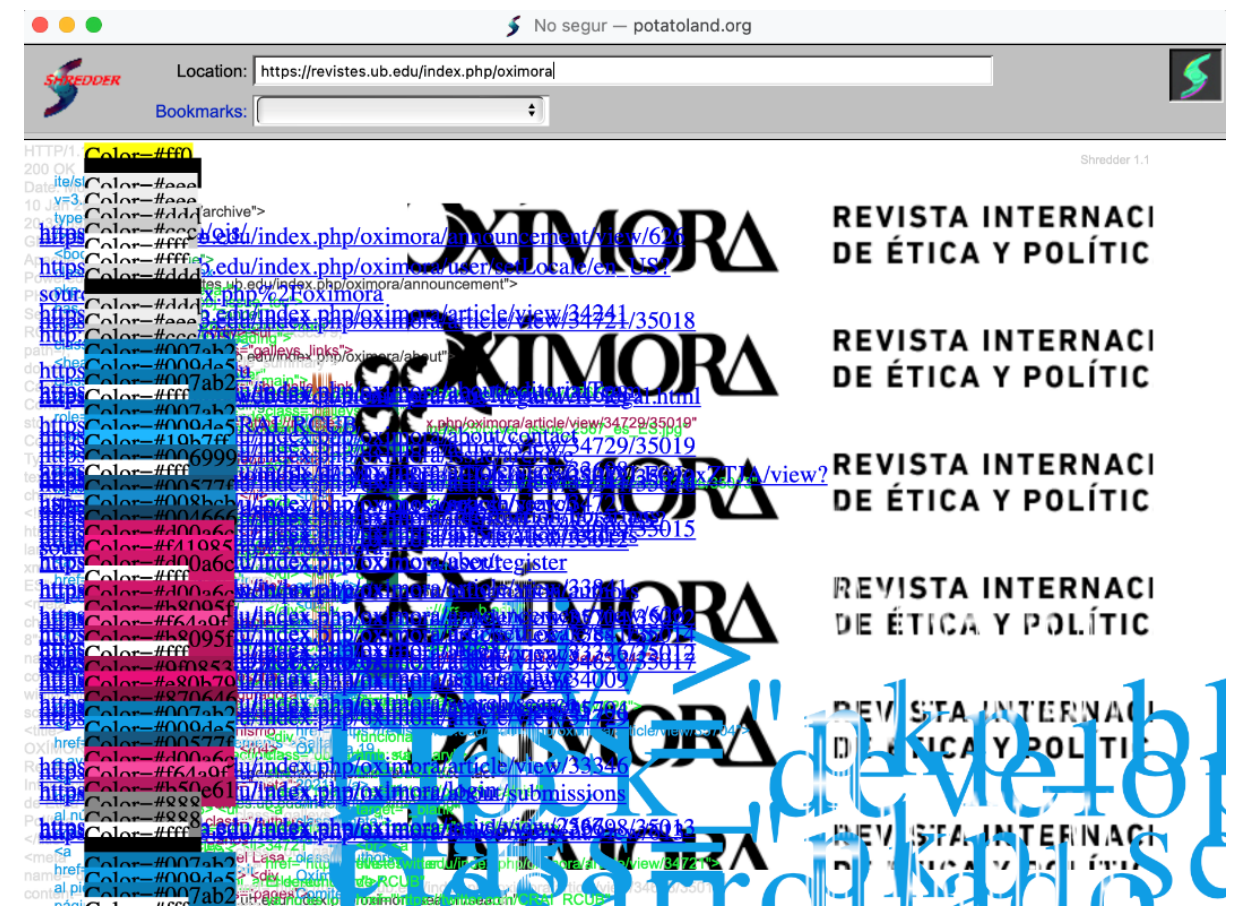

Captura de pantalla de la visualització de la web de la revista OXÍMORA segons el descodificador The Schredder de Mark Napier. CC BY-NC-SA. [online] Disponible a: http://potatoland.org/riot/ Darrer accés: 10.01.2022 
Benjamin Grosser, artista estatunidenc que se centra en els efectes culturals, socials i polítics del programari segueix l'estela de Napier. Es pot anar a la web de Grosser i baixar-se un programari anomenat ScareMail (2013) per instal-lar-te'l al teu propi ordinador. Això fet, el que passarà, és que t'hauràs baixat una extensió del navegador web que farà que el correu electrònic es torni scary per tal d'interrompre la vigilància de l'Agència de Seguretat Nacional (NSA). Ampliant el Gmail de Google, ScareMail afegeix a cada signatura de correu electrònic nova una narració generada de manera algorítmica que conté una col-lecció de termes de cerca probables de la NSA. Aquesta afegit actua com una trampa per a programes de la NSA com PRISM i XKeyscore, obligant-los a mirar absurditats. L'afegit de cada correu electrònic és únic per intentar evitar el filtratge automatitzat pels sistemes de cerca de la NSA (Grosser, 2013).

Com explica Grosser, una de les estratègies que utilitzen els programes de vigilància de correu electrònic de l'Agència de Seguretat Nacional (NSA) dels EUA és la detecció de paraules clau predeterminades. Aquests "selectors", tal i com s'hi refereixen internament, s'utilitzen per identificar comunicacions de presumptes terroristes. Així, grans col-leccions de paraules han estat codificades com perilloses, com a indicadores d'intencions subversives. El resultat és una màquina de vigilància governamental que s'executa, recopilant i cercant algorítmicament les nostres comunicacions digitals en un esforç per predir comportaments basats en paraules dels correus electrònics (Grosser, 2013).

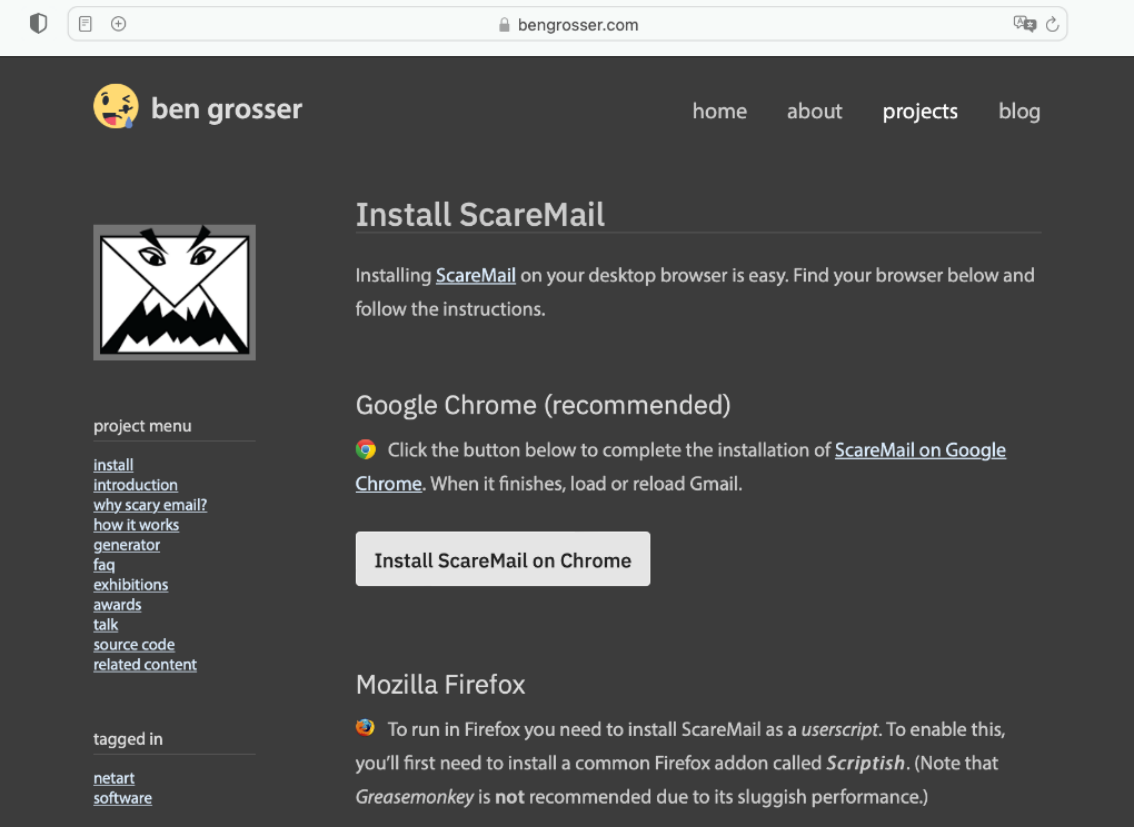

Captura de pantalla de la pàgina de descàrrega del programari lliure ScareMail de Benjamin Grosser. CC BY-NC-SA. [online] Disponible a: https://bengrosser.com/projects/scaremail/install-scaremail/ Darrer accés: 10.01.2022 
ScareMail proposa interrompre els esforços de vigilància de la NSA fent inútils els resultats de la cerca de la NSA. Al omplir tots els correus electrònics amb paraules “atemoritzants", ScareMail frustra els algorismes de cerca de la NSA aclaparantlos amb massa resultats. Si cada correu electrònic conté la paraula "trama" o "instal-lació" o "bomba", per exemple, buscar aquestes paraules es converteix en un exercici infructuós. Una cerca que ho retorna tot és una cerca que no retorna res útil. Fent això Grosser diu revelar un dels principals defectes dels esforços de vigilància de la NSA: les paraules no són iguals a la intenció (Grosser, 2013).

Un altre complement del navegador, AdNauseum (2015) de l'artista Daniel Howe i el dissenyador Mushon Zer-Aviv, bloqueja els anuncis a les pàgines web mentre fa clic simultàniament a cada anunci en segon pla: acció dual que blanqueja el perfil d'un usuari amb una pluja de dades sense sentit. A mesura que les dades recollides mostren un flux de clics devoradors, el seguiment, l'orientació i la vigilància dels usuaris esdevenen inútils. El seu objectiu anàrquic és fomentar la desconfiança entre els anunciants i les xarxes publicitàries. Aquest programari també te'l post baixar d'una web i instal-lar-te'l al teu ordinador. AdNauseam és una extensió gratuïta del navegador dissenyada per ofuscar les dades de navegació i protegir els usuaris del seguiment de les xarxes publicitàries. Al mateix temps, AdNauseam serveix com a mitjà per amplificar el descontentament dels usuaris amb les xarxes publicitàries que ignoren la privadesa i faciliten la vigilància massiva. AdNauseam s'uneix a una classe més àmplia de sistemes tècnics que intenten servir fins ètics, polítics i expressius. A la vista del fracàs de la indústria per autorregular-se o abordar d'una altra manera els excessos del seguiment de la xarxa, AdNauseam permet als usuaris individuals lluitar contra la vigilància unilateral (Howe i Zer-Aviv, 2013).

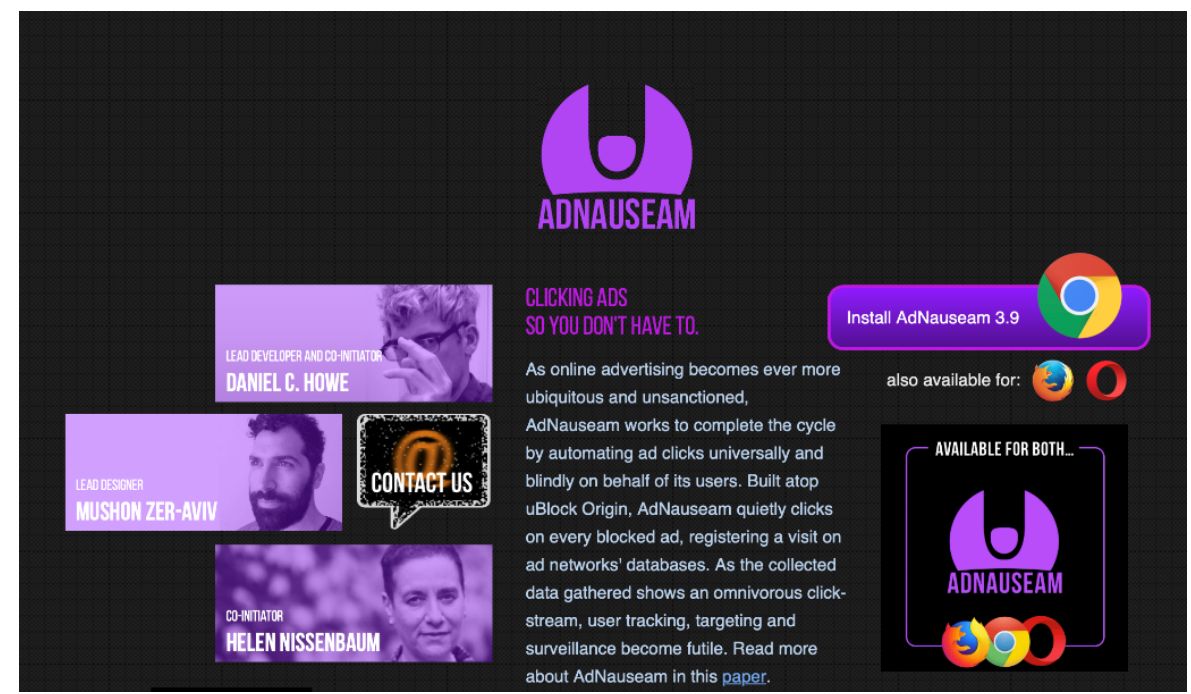

Captura de pantalla de la pàgina de descàrrega del programari lliure Adnauseamde de Daniel Howe i Mushon Zer-Aviv. CC BY-NC-SA. [online] Disponible a: https://adnauseam.io/ Darrer accés: 10.01.2022 
Napier és d'aquells artistes inaugurals que es van adonar de seguida que l'ús del programari reconfigura gran part de les nostres pràctiques socials i culturals més bàsiques i ens obliga a repensar els conceptes i les teories que desenvolupem per descriure-les. Contemporàniament a ell Manuel Castells en el també inaugural L'era de la informació (1998) definia la premissa de tot mashup: es tracta de la integració en el mateix sistema de les modalitats escrita, oral i audiovisual. A això darrer Castells ho anomenava multimèdia: la nostra cultura serà modificada pels sistemes multimèdia i ho faran per sempre, afirmava (Castells, 1998: 361). Dècades després Manovich, desenvoluparà aquest punt de vista a El programari pren el comandament (2013) i perfilarà dient que els sistemes sorgits del programari no són multimèdia, sinó sistemes híbrids. Segons Manovich els mitjans híbrids no són el mateix que les entitats multimèdia perquè no són la convergència de continguts procedents de diferents mitjans, sinó que són la confluència dels llenguatges d'aquests diferents mitjans. D'aquí el concepte d'hibridació i de mashup per substituir la idea de convivència o contigüitat de la noció ja obsoleta de multimèdia. Aquests híbrids van començar a aparèixer a partir del moment que els formats de representació, les tècniques de creació de contingut i les interfícies d'accés van ser dissociats de les bases físiques i traduïts a programari. Llavors, aquests elements van començar a interrelacionar-se i van produir nous híbrids. Aquesta, segons Manovich, és l'essència de la nova fase del metamedi ordinador que s'està vivint actualment. Les propietats i tècniques exclusives de diferents mitjans han esdevingut elements de programari que es poden combinar per vies que abans resultaven impossibles (Manovich, 2013: 151). Al mateix temps es poden afegir també altres vies tècniques de nova creació, sempre que puguin operar sobre la mateixa estructura de dades (Manovich, 2013: 173).

En aquest metamedi, avui en dia, milions de persones intercanvien fotos, textos, vídeos i música a diari a través de MySpace.com, Flickr.com, YouTube.com, i en mons virtuals, com SecondLife.com i blogs. Està emergint un espai que ha quedat estructurat per a l'expressió creativa de milions de persones que troben plataformes en línia per a la comunicació, la creativitat i el disseny. Hi ha una multitud de mecanismes per navegar i interaccionar; un contingut dels serveis web que no para de canviar i créixer; una capacitat d'afegir el nostre propi contingut, de vegades en mashup i barrejat de diferents fonts; arquitectures per a l'autoria i l'edició col-laboratives; mecanismes de seguiment dels proveïdors: tots aquests sistemes democratitzen la creativitat i la innovació perquè permeten que els fins fa poc consumidors siguin ara productors. Els usuaris són, segons la feliç expressió de Peter Weibel, prosumidors (pro/ductors i con/sumidors) (Weibel, 2013). Són els usuaris els que generen els seus propis continguts i programes, intercanvien entre si, i distribueixen lliurement en línia. 
Actualment està emergint tot un moviment entre els professionals del disseny que s'identifiquen amb la idea de "disseny obert" emulant el concepte de "codi obert". Un disseny que promou l'aplicació de principis sorgits a partir del moviment de programari lliure. Parteix de la idea que la creativitat, i la societat en general, es beneficien de les vies de comunicació obertes i de la transmissió lliure d'informació. Per això, el disseny obert busca compartir els processos de creació, distribució i fabricació d'objectes, idees o sistemes, perquè altres puguin usar-los per adaptar, reformular, produir o distribuir aquests dissenys o contingut segons les seves necessitats. La cultura del disseny obert està marcant molt ràpidament un canvi de paradigma en les indústries creatives, fent possible una economia col-laboradora d'enorme potencial tant per a dissenyadors i creadors com per a usuaris i consumidors (Narotzky, 2013).

I d'aquest entorn ve el cas d'estudi de la tipografia ZXX (2013) del coreà Sang Mun. Al llarg del seu servei a l'exèrcit coreà, Sang Mun va treballar durant dos anys com a personal d'intel-ligència especial per a l'Agència de Seguretat Nacional (NSA) dels Estats Units, aprenent de primera mà com extreure informació d'objectius de defensa. Mun va poder experimentar com la capacitat de recopilar informació vital de SIGINT (Intel-ligència de senyal) de l'agència era molt fàcil de realitzar. Aquestes habilitats s'utilitzaven a l'exterior amb finalitats de seguretat i defensa nacionals, i a l'interior per supervisar els ciutadans nord-americans. Com a dissenyador, està influenciat per aquestes experiències i es dedica a investigar maneres d'articular la nostra falta de llibertat i desenvolupar un pensament propi sobre la censura, la vigilància i una societat lliure. ZXX és un projecte que va durar un any. Sang Mun va investigar i va crear una tipografia disruptiva que pren el nom de la llista de codis de tres lletres de la Biblioteca del Congrés d'Estats Units que denoten quan un llibre està en un idioma que la màquina d'OCR (Reconeixement Òptic de Caràcters) no reconeix. El codi "ZXX" s'utilitza quan hi ha un: "Sense contingut lingüístic; No aplicable.” El projecte va començar amb una pregunta genuïna: com podem ocultar els nostres pensaments fonamentals a les intel-ligències artificials i a aquells que les desenvolupen? Sang Mun va decidir crear un tipus de lletra que fos il-legible per un programari d'escaneig de text (ja fos utilitzat per una agència governamental o per un pirata informàtic solitari), dirigint la informació o, de vegades, sense donar-ne cap. ZXX es pot aplicar a grans quantitats de dades o a correspondència personal. Així, Mun va dibuixar sis tipus de lletra diferents (Sans, Bold, Camo, False, Noise i Xed) per generar permutacions interminables i frustrar les intel-ligències de les màquines d'una manera diferent. Llavors va oferir la tipografia com a descàrrega gratuïta amb l'esperança que la fes servir el màxim de gent possible (Mun, 2013). 


\section{ZXX ABCDEFGHIJKLMNOPQRST}

Bol UVWXYZabcdefghijklmn

d// opqrstuvwxyz00123450

/// 789\%।! ? @\#/\&*( ) , : \$f¥

$/ / /+x \div \pm-=-"$ - o* afy $y_{4} \frac{1}{2} z_{4}[]$

San ABCDEFGHIJKLMNOPQRST

s// UVWXYZabcdefghijklmn

/// opqrstuvwxyz00123458

/// 789\%】! ?@\#/\&*( ) . : :\$f\#

$/ / /+x \div \pm-=-\ldots$ - 'o*afyfifl? []

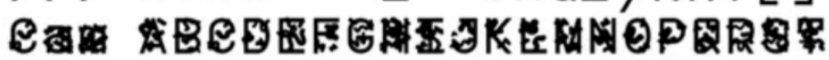

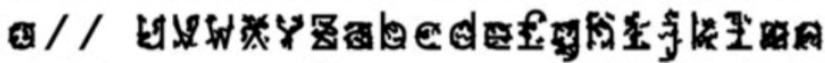

/ / 1

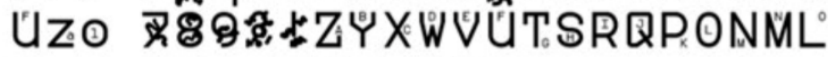

hv/ K JIHGF EDOBAZYXwVut's

/// gponmlikjihgfedcbag98

N@I 7.6543210! ? ABCDEFG

SE/ KLANOPQRSTUWWXYZabod

/ / efghiglkmopgnatuvw

Xed yzQO123456789,2 ABBQBE

98/ FGHIJKLMNORERSTWWWXK

98. Zabedefghijkkmapres

pt. tutVuXXYZ001234587892\%

Type Specimen de la tipografia $Z X X$ de Sang Mun CC BY-NC-SA. [online] Disponible a: https://cargocollective.com/zxx/ Darrer accés: 10.01.2022

Mun considera que ZXX és una crida a l'acció, tant pràctica com simbòlica, per plantejar preguntes sobre la privadesa. Però representa una urgència més àmplia: com es pot utilitzar el disseny políticament i socialment per a la codificació i descodificació dels pensaments de la gent? Què és un disseny gràfic que és inherentment secret? Com pot el disseny gràfic reforçar la privadesa? I, realment, com pot el procés de disseny engendrar una actitud proactiva cap al futur, i per tant, el nostre present? La nostra vida al ciberespai està sobrecarregada d’informació personal impalpable i extensa que es recull, s'intercepta, es desxifra, s'analitza i s'emmagatzema. Amb aquesta informació, el govern i les corporacions poden crear fàcilment una arquitectura informativa que ens integra dins de les estructures de la World Wide Web i les xarxes socials. Restringir i reprimir les nostres eines de comunicació sota el nom de "seguretat nacional" és només un petit pas cap a una societat totalitària. Segons Mun, aquesta violència no física però ideològica és la que ens permet caure en un 
silenci letàrgic. Però realment, no hem de tenir por de qüestionar les contínues intromissions de les autoritats (Mun, 2013).

\section{Via III. Apropiació de tecnologies de vigilància amb finalitats subversives}

Com subratlla Morrison, a la nostra vida quotidiana, utilitzant targetes de crèdit, càmeres web, etiquetant les nostres imatges a Facebook, navegant per una ciutat amb els nostres telèfons intel-ligents, participem constantment com a ciutadans en la societat de vigilància (Morrison, 2013). En aquest sentit, la vigilància és participativa. Tanmateix, en el disseny i l'art de la vigilància, la participació esdevé una tàctica de crítica política i d'acció subversiva. Aquest és sens dubte el cas de Pulse Tank (2008) de Lozano-Hemmer.

L'artista mexicà Rafael Lozano-Hemmer a les seves instal-lacions multimèdia tracta temes com la memòria, la presència, les formes de control i la violència vehiculats a través d'instal-lacions electròniques lumíniques. En les seves obres la llum és la metàfora de la vida i la raó, però també la lliga als usos com a eina de control que l'artista defineix com a "llum violenta". Aquest terme inclou tots els tipus de llum que s'utilitzen per a la vigilància, l'interrogatori i les formes d'intimidació humana. Per a Lozano-Hemmer, les tecnologies de vigilància són una part inevitable de la nostra societat globalitzada; són eines per a la generació i control de dades que també es poden utilitzar a través de l'art de forma momentània i lúdica, desestabilitzant formes binàries de poder i control (Arozqueta, 2018).

Per exemple Pulse Tank (2008) resumeix molt bé aquestes connotacions. La instal-lació consta de dos dipòsits d'aigua de vidre rectangulars situats a uns dos metres sobre el terra, dins d'una habitació il-luminada per un focus situat al sostre de la sala. Es convida als visitants a introduir els dits en un dels quatre cilindres instal-lats als laterals dels tancs (a vegades també es fa amb les mans). En tocar els sensors, un ordinador detecta la freqüència cardíaca dels participants i activa un motor que crea ones d'aigua al ritme del pols del visitant. Aquestes ones d'aigua són projectades a la paret. D'aquesta manera la intimitat de la persona que està tocant el sensor i mostrant les seves pulsacions queda al descobert, el seu batec s'ha fet públic (Lozano-Hemmer, 2018). 


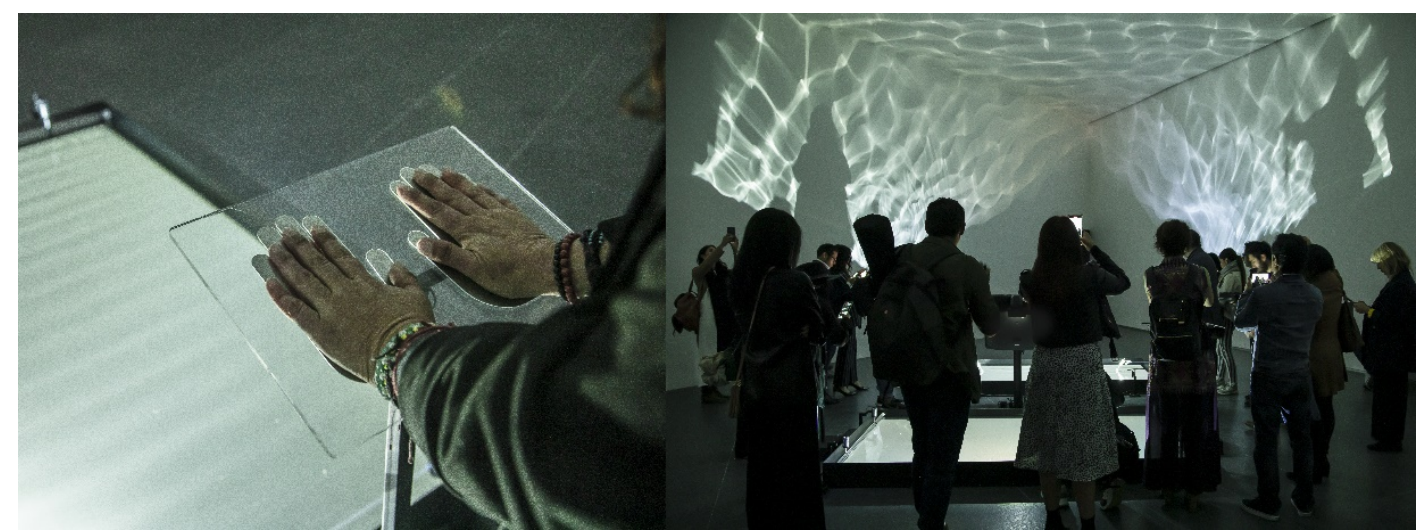

Pulse Tank (versió 2020 - Arte Abierto, Mexico City, México) de Rafael Lozano-Hemmer a CC BY-NC-SA. [online] Disponible a: https://www.lozano-hemmer.com/pulse_tank.php Darrer accés: 10.01.2022

En moltes de les seves exposicions Lozano-Hemmer monitoreja els visitants des del primer moment que accedeixen a la sala. Per exemple, a Zoom Pavillion (2015) Lozano-Hemmer presentava en col-laboració amb el polonès Krzysztof Wodiczko una instal-lació on es reflectien en els murs imatges en blanc i negre dels visitants preses per càmeres de vigilància, fent ús de sistemes de reconeixement facial i d'algorismes per monitoritzar les seves relacions en temps i espai. Zoom Pavilion és alhora una plataforma experimental d'autorepresentació i un microscopi gegant per connectar el públic entre ells i seguir-los. Les càmeres robòtiques independents fan zoom per amplificar les imatges del públic amb un augment de fins a 35x. Les seqüències de zoom desorienten, ja que canvien tot el paisatge de la imatge des de plans amples fàcilment reconeixibles de la multitud fins a primers plans abstractes. Tota la instal-lació es troba en un estat fluid de moviment de càmera, destacant diferents participants i creant una animació en constant canvi basada en l'amplificació òptica i el seguiment (Lozano-Hemmer, 2015).

En altres exposicions Lozano-Hemmer ha rebut els visitants forçant-los a buidar les butxaques com passa en els dispositius de vigilància dels museus, els aeroports i els edificis governamentals. Please Empty Your Pockets (2010) és una instal-lació que consta d'una cinta transportadora amb un escàner informatitzat que registra i acumula tot el que hi passa per sota. El públic pot col-locar qualsevol petit article a la cinta transportadora, per exemple claus, carnets d'identitat, carteres, tiquets, blocs de notes, telèfons, monedes, ninots, targetes de crèdit, etc. Un cop passen per sota de l'escàner, els objectes tornen a aparèixer. A mesura que un article s'elimina de la cinta transportadora (el propietari se'l emporta), deixa enrere una imatge projectada d'ell mateix, que després s'utilitza per acompanyar objectes futurs. La peça enregistra fins a 600.000 objectes que es mostren al costat de nous que s'afegeixen a la instal-lació. El visitant viu aquesta obra de manera invasiva i recorda que l'exposició no és res en comparació amb com els nostres moviments, 
converses i dades personals són recopilats, arxivats i utilitzats per altres cada dia, sovint mitjançant telèfons intel-ligents configurats per fer un seguiment de tots els nostres moviments (Lozano-Hemmer, 2010).

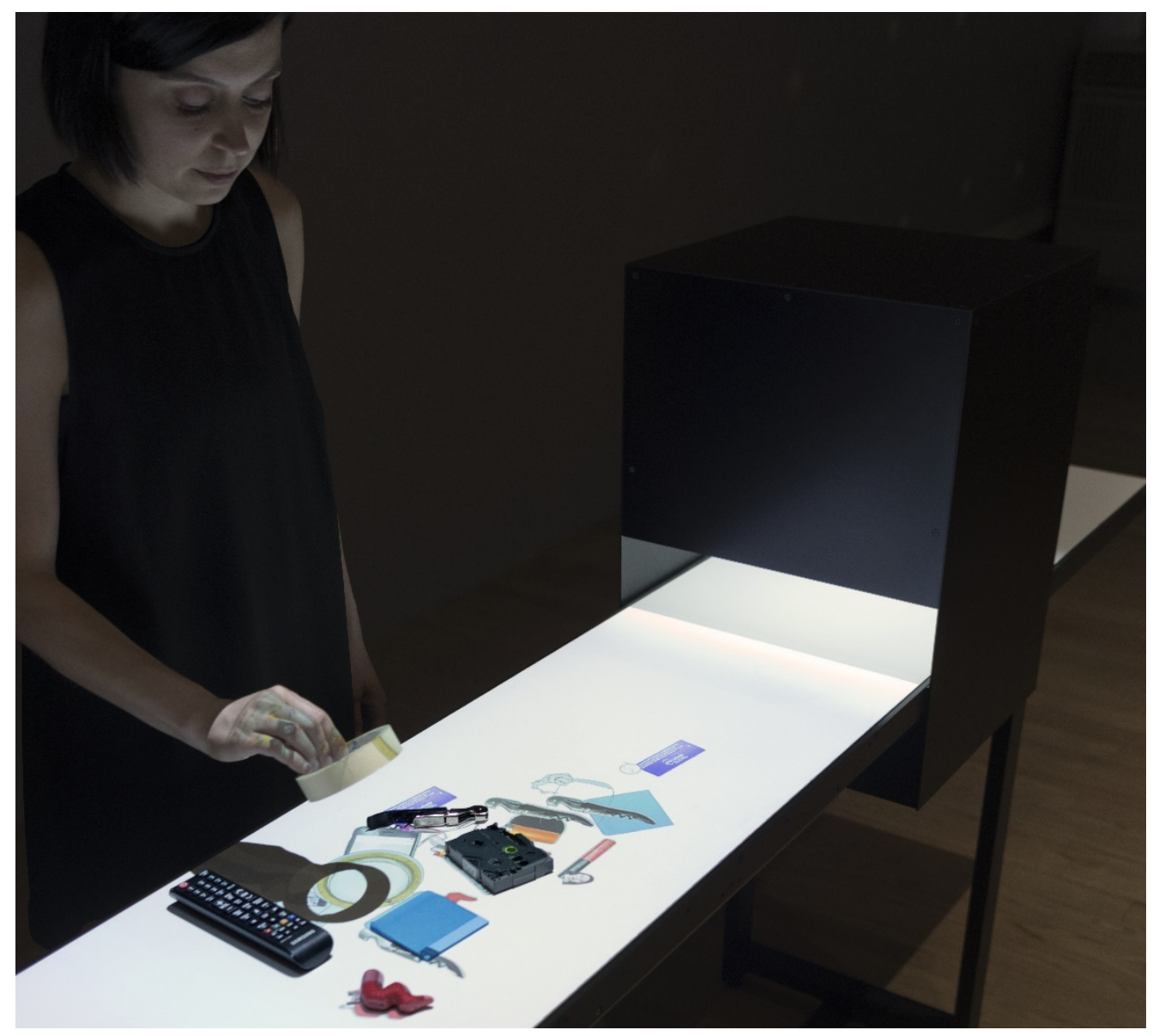

Pulse Tank (versió 2015 - bitforms gallery, New York City, New York, United States) de Rafael Lozano-Hemmer a CC BY-NC-SA. [online] Disponible a: https://www.lozano-hemmer.com/please_empty_your_pockets.php Darrer accés: 10.01.2022

En totes aquestes instal-lacions Lozano-Hemmer busca influir o afectar la percepció, cridar a la participació social (també en termes d’interacció, ús d'espais públics i sensibilització social) i al diàleg amb l'entorn ambiental. Lozano-Hemmer vol fer-nos conscients de l'activitat de seguiment a la que estem sotmesos (per imatges, interfícies i dispositius de seguiment) i ens vol fer reaccionar davant el fet que aquests dispositius ja anticipen els nostres moviments, desitjos i trajectòries. El treball de Lozano-Hemmer es pregunta sobre com els sistemes de vigilància, el capital global i les tecnologies digitals han reconfigurat les nocions d'espai públic, i del propi públic (Ravetto, 2010: 121). 
En definitiva, aquestes obres de disseny i art digitals tracten sobre la línia en què la naturalesa humana es troba amb la tecnologia. Internet ens introdueix en un món on la propietat es defineix mitjançant maquinari i programari, dades i instruccions. La informació es pot reciclar i reproduir de maneres aparentment interminables i distribuir-se en contextos sempre canviants; l'espai alternatiu de la xarxa resisteix el nostre model físic tradicional de propietat, drets d'autor i marca. Com traduïm la nostra necessitat de poder i control en aquest nou mitjà i en què, en tot cas, cedim? Estem disposats a ser fiscalitzats a cada segon? La manera com ens relacionem amb aquesta tecnologia acabarà per determinar com ens relacionem entre nosaltres.

I com els projectes ressenyats en aquest article propicien la producció de pensament crític? Rafael Dernbach a Hacking the vision machine (2014) estableix una analogia entre l'art i el disseny de la vigilància i les tècniques d'hackejar i crackejar. L'artista i el dissenyador no treballen sobre un "codi informàtic", sobre un establishment anem a dir, sinó que el que subverteixen són els discursos i enfocaments socials, posant de manifest noves visions crítiques i desarticulant (desconstruint) la mirada del poder. L'art i el disseny de la vigilància ofereixen imatges inusuals que hackegen els mecanismes invisibles del poder inspector a què les persones estan sotmeses. En certa manera el que es realitza és una pirateria de les estructures de control.

Igual que els pirates informàtics, els autors ressenyats en aquest article utilitzen imatges produïdes per institucions sentinella i les manipulen. Fan palpables els confinaments virtuals de les estructures de control mitjançant la pertorbació dels procediments reals: imitant i reutilitzant les imatges d'escorcoll fan visibles les presumpcions i els punts cecs de la societat tecnocràtica que regeix les estructures particulars que produeixen aquestes imatges. Aquest desviament de les imatges de control permet desxifrar el "codi font", els procediments i les presumpcions del capitalisme digital (Dernbach, 2014: 387). Igual que els pirates informàtics són capaços de penetrar sistemes tecnològics que, d'altra manera, podrien semblar infal-libles, els artistes i els dissenyadors també són capaços de reconduir, i per tant de reescriure, els programes culturals i reprogramar els valors socials que donen lloc a les noves tecnologies (Derch, 2014: 388). Per tant, aquestes obres es poden considerar com a models de resistència visual i pràctica d'imatge crítica en societats de control. 


\section{Bibliografia}

Arozqueta, Claudia. (2018). Llum polisèmica: la llum com a material contradictori en l'obra de Rafael Lozano-Hemmer. Artnodes, 21, 146-153. https://doi.org/10.7238/a.voi21.3185.

Beyes, T., Leeker, M. i Schipper, I. (2017). Performing the digital: performance studies and performances in digital cultures. Transcripció-Verlag.

Castells, M. (1998). L'era de la informació. Madrid: Alianza. Vols I, II i III.

Cirio, P. (2011). Streetghosts. Pàgina Web Oficial de Paolo Cirio a https://paolocirio.net/work/street-ghosts/

Cirio, P. (2016). Face to Facebook - Hacking Monopolism Trilogy. Pàgina Web Oficial de Paolo Cirio a https://paolocirio.net/work/face-to-facebook/

Dernbach, R. (2014). Hacking the Vision Machine: Farocki's and Paglen's detourning of control images. Revista Teknokultura, 11(2), 383-403. https://revistas.ucm.es/index.php/TEKN/issue/view/2712

Howe, D. i Zer-Aviv. (2015). M. AdNauseum. https://adnauseam.io/

González Díaz, P. (2014). Reacciones en el New Media Art ante la vigilancia y el control de datos en la Red: nuevos paradigmas (2001-2010). Revista Teknokultura, 11(2), 349-382. https://revistas.ucm.es/index.php/TEKN/issue/view/2712

Grosser, B. (2013). ScareMail. Pàgina Web Oficial de Benjamin Grosser a https://bengrosser.com/projects/scaremail/

King, A. (2015). Subvertir la vigilància. Nature, 524, 413-414. https://doi.org/10.1038/524413a

Lozano-Hemmer, R. (2010). Please Empty Your Pockets. Pàgina Web Oficial de Rafael Lozano-Hemmer a https://www.lozano-hemmer.com/please_empty_your_pockets.php

Lozano-Hemmer, R. i Wodiczko , K. (2015). Zoom Pavillion. Pàgina Web Oficial de Rafael Lozano-Hemmer a https://www.lozano-hemmer.com/zoom_pavilion.php

Lozano-Hemmer, R. (2018). Pulse Tank. Pàgina Web Oficial de Rafael LozanoHemmer a https://www.lozano-hemmer.com/pulse_tank.php

Manovich, L. (2013). El software toma el mando. Barcelona: Editorial UOC, ProQuest Ebook Central, http://ebookcentral.proquest.com/lib/bibliouocsp-ebooks/detail.action?docID $=4735140$

Morozov, E. (2021). Capitalismo digital, ¿cuáles son las posibles salidas? Traducción e introducción a cargo de Ekaitz Cancela y Aitor Jiménez. Teknokultura (18), 211-217. https://revistas.ucm.es/index.php/TEKN/issue/view/3794

Mun, S. (2013). Making Democracy Legible: A Defiant Typeface. The Gradient a https://walkerart.org/magazine/sang-mun-defiant-typeface-nsa-privacy 
Moll, J. (2016). The Virtual watchers a http://www.virtualwatchers.de/VW.html

Moll, J. (2017). The Dating Brokers a https://datadating.tacticaltech.org/auction

Moll, J. (2021). Pàgina Web Oficial Joana Moll a http://www.janavirgin.com/

Morrison, E. (2013). No amigable amb l'usuari: l'art de la vigilància com a actuació participativa. Teatre, 43, 5-23. DOI:10.1215/01610775-2284856.

Morrison, E. (2015). La societat de vigilància necessita teoria del rendiment i pràctica artística. International Journal of Performance Arts and Digital Media, 11, 125-130. DOI:10.1080/14794713.2015.1084812

Napier, M. (1998). The Shredder. Pàgina Web Oficial de Marc Napier a http://www.potatoland.org/shredder/about.html

Napier, M. (1999). Riot. Pàgina Web Oficial de Marc Napier a http://www.potatoland.org/riot/

Narotzky, Viviana. (2013). Congrés Open Design / Shared Creativity, FAD, Barcelona. http://fad.cat/congres/old/2012/es/

Ravetto-Biagioli, K. (2010). A l'ombra d'imatges: Rafael Lozano-Hemmer i l'art de la vigilància. Representacions, 111 (1), 121-143. https://www.jstor.org/stable/10.1525/rep.2010.111.1.121

Weibel, Peter. (2009).You_ser 2.o: celebració per al consumidor, Karlsruhe, ZKM. http://wwwo2.zkm.de/you/index.php?lang=en 